AperTO - Archivio Istituzionale Open Access dell'Università di Torino

\title{
Marine fungi as source of new hydrophobins
}

\section{This is the author's manuscript}

Original Citation:

\section{Availability:}

This version is available http://hdl.handle.net/2318/1589536

since 2016-08-29T12:21:40Z

Published version:

DOI:10.1016/j.ijbiomac.2016.08.037

Terms of use:

Open Access

Anyone can freely access the full text of works made available as "Open Access". Works made available under a Creative Commons license can be used according to the terms and conditions of said license. Use of all other works requires consent of the right holder (author or publisher) if not exempted from copyright protection by the applicable law. 
This Accepted Author Manuscript (AAM) is copyrighted and published by Elsevier. It is posted here by agreement between Elsevier and the University of Turin. Changes resulting from the publishing process - such as editing, corrections, structural formatting, and other quality control mechanisms - may not be reflected in this version of the text. The definitive version of the text was subsequently published in INTERNATIONAL JOURNAL OF BIOLOGICAL MACROMOLECULES, 92, 2016, 10.1016/j.ijbiomac.2016.08.037.

You may download, copy and otherwise use the AAM for non-commercial purposes provided that your license is limited by the following restrictions:

(1) You may use this AAM for non-commercial purposes only under the terms of the CC-BY-NC-ND license.

(2) The integrity of the work and identification of the author, copyright owner, and publisher must be preserved in any copy.

(3) You must attribute this AAM in the following format: Creative Commons BY-NC-ND license (http://creativecommons.org/licenses/by-nc-nd/4.0/deed.en), 10.1016/j.ijbiomac.2016.08.037

The publisher's version is available at:

http://linkinghub.elsevier.com/retrieve/pii/S0141813016311928

When citing, please refer to the published version.

Link to this full text:

http://hdl.handle.net/2318/1589536 


\title{
Marine fungi as source of new hydrophobins
}

- Paola Cicatiello ${ }^{\text {, }}$

- $\quad$ Alfredo Maria Gravagnuolo ${ }^{\mathrm{a}}$,

- Giorgio Gnavi

- Giovanna Cristina Varese $e^{b}$,

- Paola Giardina $^{\mathrm{a},}$,

a Department of Chemical Sciences, University of Naples Federico II, via Cintia 4, I-80126 Naples, Italy

${ }^{\mathrm{b}}$ Department of Life Sciences and Systems Biology, University of Turin, viale P.A. Mattioli 25, I-10125 Turin, Italy

http://dx.doi.org/10.1016/j.ijbiomac.2016.08.037

\section{Highlights}

23 Marine fungi have been analyzed to identify hydrophobin producers.

6 New hydrophobins have been isolated.

4 Proteins belong to class I and 2 to class II hydrophobins.

One of the new class I hydrophobins stably changes the wettability of a crystalline silicon chip.

One of the new class II hydrophobin is endowed with remarkable emulsification capacity.

\begin{abstract}
Hydrophobins have been described as the most powerful surface-active proteins known. They are produced by filamentous fungi and exhibit a distinct amphiphilic structure determining their selfassembly at hydrophilic-hydrophobic interfaces and surfactant properties which have been demonstrated to be useful for several biotechnological applications. The marine environment represents a vast natural resource of new molecules produced by organisms growing in various stressful conditions. This study was focused on the screening of 100 marine fungi from Mycoteca Universitatis Taurinensis (MUT) for the identification of new hydrophobins. Four different methods were set up to extract hydrophobins of class I and II, from the mycelium or the culture broth of fungi. Six fungi were selected as the best producers of hydrophobins endowed with different characteristics. Their ability to form stable amphiphilic films and their emulsification capacity in the presence of olive oil was evaluated.
\end{abstract}




\section{Graphical abstract}

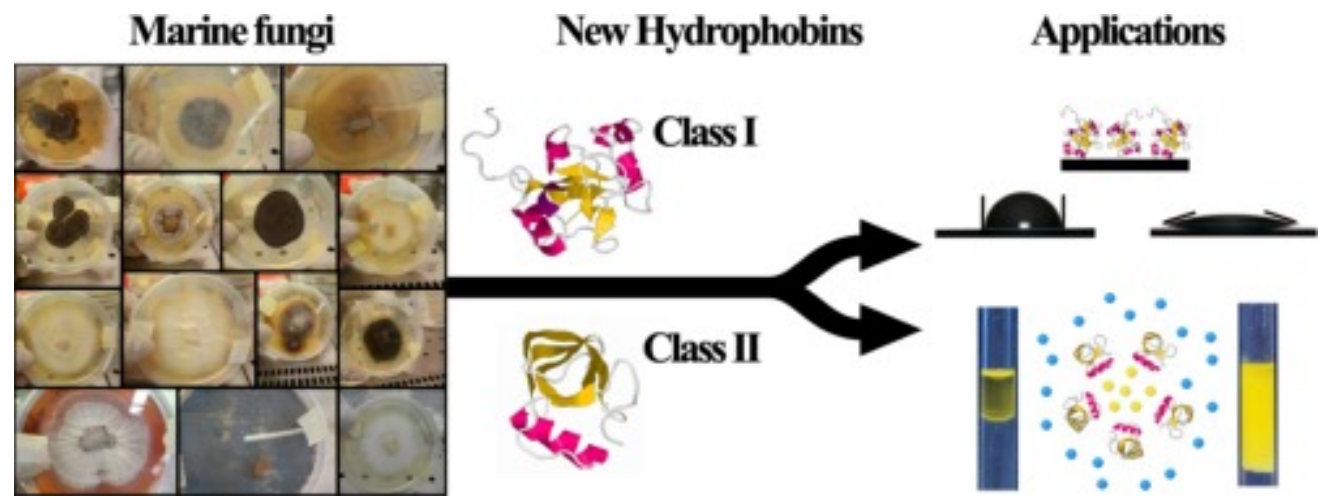

Figure options

\section{Keywords}

- Biosurfactants;

- Marine microorganisms;

- Self-assembly;

- Surface wettability;

- Emulsion;

- Protein coating

\section{Introduction}

Hydrophobins (HFBs), small proteins (about 100 amino acids) typical of filamentous fungi, have been described as the most powerful surface-active proteins known and their activity is intrinsic to the proteins themselves [1] and [2]. Indeed, on one side of their molecular surface, some exposed hydrophobic aliphatic side chains form a flat hydrophobic patch, whilst polar or charged residues are confined to the other side [3] and [4]. The hydrophobic patch could be involved in interaction with an identical protein partner that obscures the hydrophobic region. This allows miscibility with the bulk water phase until reaching an air-water interface or other non-polar surface, where they probably dissociate and re-orient with the hydrophobic surface exposed to the interface [5]. Several features of fungal development have been attributed to these proteins [6], e.g. coating of spores, aerial hyphae and fruiting bodies with a water-repellent and adhesive layer allowing the fungus to escape from the liquid medium and to live in adhesion on different surfaces [7]. HFBs show very little conservation of their sequence, apart from the pattern of eight Cys residues implicated in the formation of four disulfide bridges (Cys1-Cys6, Cys2-Cys5, Cys3-Cys4, Cys7- Cys8) [8]. They have been split in two groups, class I and class II, based on structural differences and properties of the aggregates they form [9]. Class I HFBs form highly insoluble aggregates that have the appearance of distinct rodlets and, similarly to amyloid fibrils, are characterized by cross $\beta$-structure [10]. These assemblies show outstanding stability and can be depolymerized in $100 \%$ trifluoroacetic acid (TFA) whereas class II HFBs form less stable polymers that are soluble in some organic solvents or SDS aqueous solution, and lack the rodlet appearance of class I HFBs [11]. Both types of HFBs have been used for several biotechnological applications, such as dispersion of hydrophobic materials, foam stabilization in food products, surface coating and modification of the 
surface wettability, immobilization of enzymes, peptides, antibodies and nanomaterials on various surfaces [12], [13], [14] and [15].The marine environment host a huge biodiversity of (micro) organisms, and fungi make up a large part of them [16]. Marine fungi form an ecological, and not a taxonomic group. These species live in a stressful habitat, under cold, lightless, high-pressure conditions or other types of mechanical stress. Their capability to survive in different environmental conditions makes them attractive to isolate new molecules [17], [18] and [19]. The aim of the present study is to identify marine fungi as source of HFBs.

\section{Material and methods}

\subsection{Marine fungi}

Marine fungi were isolated and identified from the seagrass Posidonia oceanica, the green alga Flabellia petiolata and the brown alga Padina pavonica collected nearby Elba Island in the Mediterranean Sea as previously described [20], [21] and [22] and are preserved at the Mycoteca Universitatis Taurinensis (MUT).

\subsection{Culture conditions}

Each marine fungal strain was maintained through periodic transfer on agar plate at $20^{\circ} \mathrm{C}$. The strains were grown in multiwell plates $\left(9.5 \mathrm{~cm}^{2}\right.$ cell growth area) in 3 different liquid media XNST30 (malt extract 3 g/L; yeast extract 3 g/L; NaCl 30 g/L; 10 g/L glucose and 5 g/L peptone), PDY15 (24 g/L potato dextrose; $5 \mathrm{~g} / \mathrm{L}$ yeast extract and $15 \mathrm{~g} / \mathrm{L} \mathrm{NaCl})$ and $\mathrm{WM}$ (10 g/L glucose; $2 \mathrm{~g} / \mathrm{L}$ peptone; $1 \mathrm{~g} / \mathrm{L}\left(\mathrm{NH}_{4}\right)_{2} \mathrm{SO}_{4} ; 0.5 \mathrm{~g} / \mathrm{L} \mathrm{MgSO}_{4} \cdot 7 \mathrm{H}_{2} \mathrm{O} ; 0.875 \mathrm{~g} / \mathrm{L} \mathrm{KH}_{2} \mathrm{PO}_{4} ; 0.125 \mathrm{~g} / \mathrm{L} \mathrm{K}_{2} \mathrm{HPO}_{4}$; $0.1 \mathrm{~g} / \mathrm{L} \mathrm{CaCl} 2 \cdot 2 \mathrm{H}_{2} \mathrm{O} ; 0.1 \mathrm{~g} / \mathrm{L} \mathrm{NaCl} ; 0.05 \mathrm{~g} / \mathrm{L} \mathrm{MnCl}_{2} ; 0.001 \mathrm{~g} / \mathrm{L} \mathrm{FeSO}_{4}$ ) at 2 different temperatures $\left(20-28{ }^{\circ} \mathrm{C}\right)$ in triplicate for 10 days. The inoculum was carried out by addition of mycelium disks (5 mm diameter) taken from actively growing cultures on agar plates in $7.5 \mathrm{~mL}$ of medium or by adding $0.5 \mathrm{~mL}$ of a suspension in $0.9 \% \mathrm{NaCl}, 0.1 \%$ Tween 80 of mycelium mechanically broken by glass beads. In order to extract sufficient amounts of HFBs, marine fungi were grown in $100 \mathrm{~mL}$ conical flasks containing $50 \mathrm{~mL}$ of the selected medium. Fungi were grown in the dark at $200 \mathrm{rpm}$ for 10 days.

\subsection{Extraction of class I and class II HFBs from the culture broth}

Proteins were aggregated by air bubbling, using a Waring blender. Foam was collected and treated with $20 \%$ trichloroacetic acid (TCA) and was centrifuged after $12 \mathrm{~h}$ incubation at $4{ }^{\circ} \mathrm{C}$ in static. In order to extract class I HFB candidates, the obtained precipitate was treated by $100 \%$ TFA in a bath sonicator, dried using a stream of nitrogen and then dissolved in a $60 \%$ ethanol solution, while it was directly treated by $60 \%$ ethanol to dissolve class II HFBs.

\subsection{Extraction of class I and class II HFBs from the mycelium}

To extract Class II HFBs, mycelia were washed by water and proteins were extracted using 60\% ethanol in a bath sonicator and, after centrifugation, the supernatant was collected.

To extract class I HFBs, mycelia were firstly washed by $2 \%$ SDS, several times by water and once by $60 \%$ ethanol to remove soluble proteins, contaminants and the detergent. The residue was freezedried, treated by TFA using a bath sonicator to extract the protein from the wall of the mycelium. After centrifugation of the TFA extract, the supernatant was dried using a stream of nitrogen, dissolved in $60 \%$ ethanol and centrifuged again. The new supernatant was lyophilized and proteins 
were extracted at the interphase using a chloroform:methanol:water mixture 1:2:2 v/v in a bath sonicator. After centrifugation, the precipitate was freeze-dried, treated by TFA in a bath sonicator, dried in a stream of nitrogen and dissolved in $60 \%$ ethanol.

\subsection{Analysis of the purified proteins}

Protein concentrations were evaluated using the PIERCE $660 \mathrm{~nm}$ Protein Assay kit using bovine serum albumin as standard. The purity and the molecular weight of the extracted samples were evaluated by SDS-PAGE (15\% acrylamide), and silver stained.

\subsection{Water contact angle analysis of the functionalized surfaces}

Contact angle measurements were performed on a KSV Instruments LTD CAM 200 Optical Contact Angle Meter coupled with drop shape analysis software. Each contact angle was calculated as the average of two drops of $5 \mu \mathrm{L}$, spotted on different points of the crystalline silicon chip.

\subsection{Evaluation of emulsifying properties of HFBs}

HFBs were dissolved in $50 \mathrm{mM}$ phosphate buffer $\mathrm{pH} 7$ at $0.05 \mathrm{mg} \mathrm{ml}^{-1}$. Solutions were mixed by vortexing for 2 min with olive oil (25\% v/v) and left standing for $24 \mathrm{~h}$. To evaluate the emulsification capacity of the samples the height of the emulsion phase was monitored.

\section{Results and discussion}

\subsection{Growth conditions of marine fungi}

Twenty-three fungi were selected from a pool of 100 marine fungal strains on the base of the ability to produce foam during the growth in shaken cultures, thus indicating the production of biosurfactants. The list of these strains is reported in Table 1.

Table 1.

List of the screened fungal strains with their MUT code and the original substrate of isolation. The asterisks indicate conditions in which they grew. The grey boxes correspond to the best growth conditions in which proteins were extracted.

\section{$\underline{\text { Table options }}$}

Subsequently, the growth conditions of the selected fungi in liquid medium were optimized in multiwell plates changing parameters such as the temperature, 20 and $28{ }^{\circ} \mathrm{C}$, and the composition of the culture broths. Three cultural broths, commonly used for fungal growth, XNST30, PDY15 and $\mathrm{WM}$, characterized by different $\mathrm{C} / \mathrm{N}$ ratio and salt concentrations, were tested. The growths were performed at two temperatures, 20 and $28{ }^{\circ} \mathrm{C}$, in triplicate for 10 days. Most of the strains grew in more than one condition, however the best combinations of parameters were selected on the basis of the abundance of the produced mycelia (Table 1). Three strains, MUT 4871, 4857 and 4860, only grew when the culture broths were inoculated by addition of mycelia mechanically broken by glass beads, not by addition of mycelium disks from agar plates. When results were comparable, the WM poor medium was preferentially selected to reduce the presence of contaminant molecules in the purified samples. 


\subsection{Extraction of class I and class II HFBs}

In order to extract sufficient amounts of HFBs, marine fungi were grown in conical flasks for 10 days and separated from the culture broths by filtration. Four different extraction methods were set up to extract HFBs belonging to Class I and Class II from both the mycelium and the culture broth, were set up (Fig. 1). The capability of HFBs to migrate at the water/air interface was exploited to extract the secreted proteins by bubbling the culture broth, while the cell wall associated proteins were isolated from the dried mycelium by solvent extraction. The requirement of the TFA treatment to solubilize the Class I HFBs was exploited to discriminate between the two classes. Since Coprinellus sp. MUT 4897 belongs to the basidiomycetes which exclusively produce class I HFBs [9], the extraction methods for this class were only used in this case.

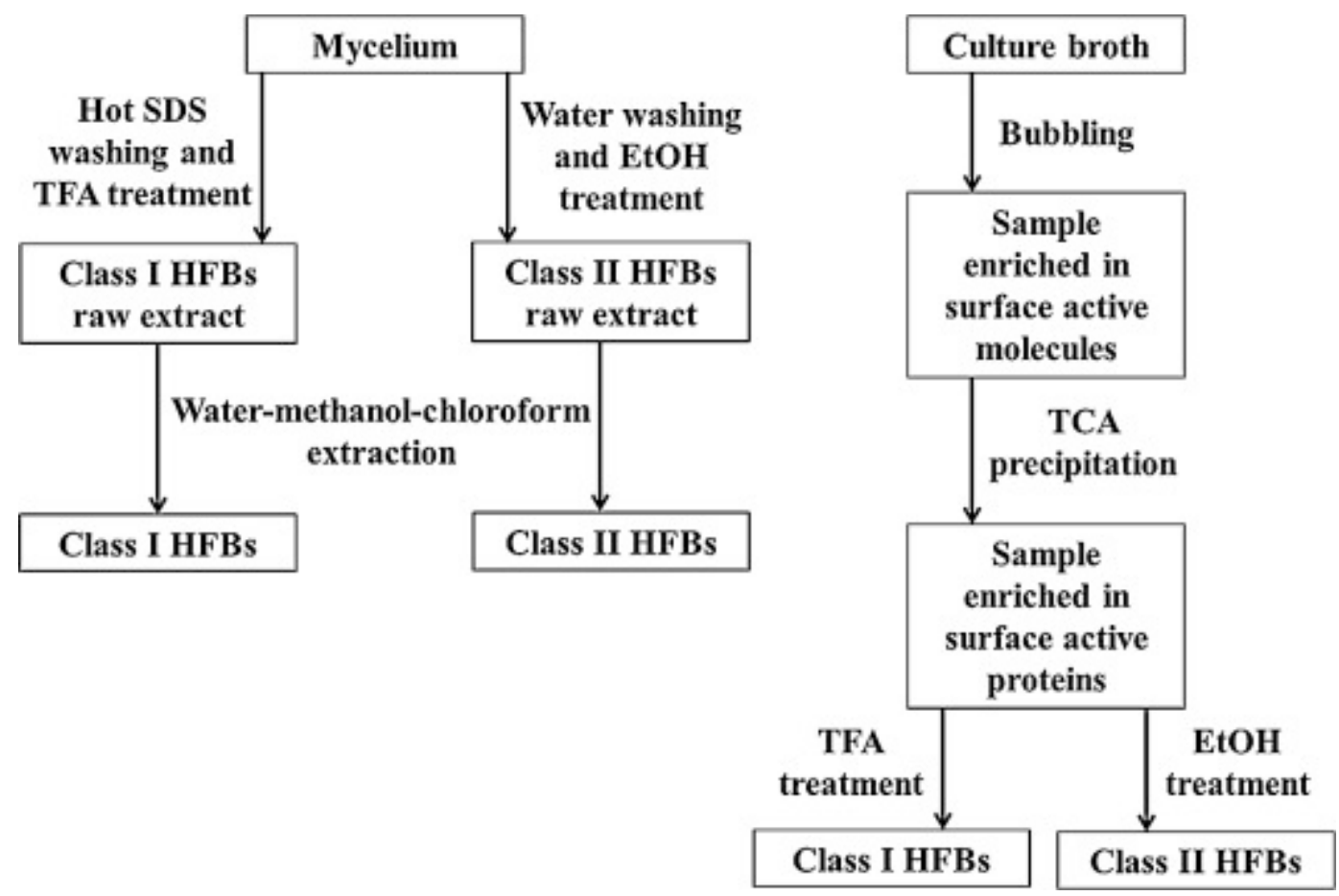

Fig. 1.

Scheme of the procedures set up to extract Class I or Class II HFB, associated to the mycelium wall or secreted in the culture broth.

\section{Figure options}

Adequate amounts of putative HFBs were extracted from 6 strains, and analyzed by SDS-PAGE (Fig. 2). The developed procedures allowed us to obtain quite homogeneous protein samples. The molecular weights of the extracted proteins ranged between 11 and $35 \mathrm{kDa}$, as observed in most of the known HFBs. 


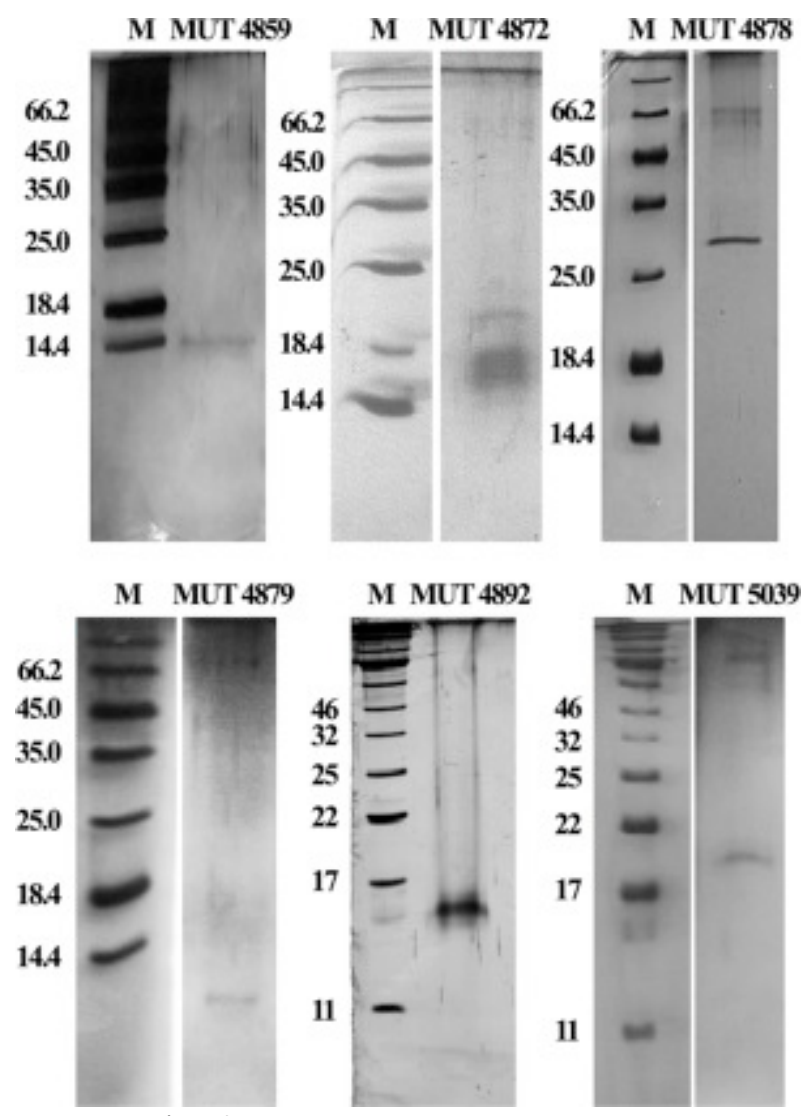

Fig. 2.

SDS-PAGE analysis of the extracted proteins. $\mathrm{M}$ is the molecular weight marker, the MUT code of the strain from which the protein was extracted, is reported in each panel.

Figure options

\subsection{Analysis of the HFB functions}

To test the ability of these putative HFBs to self-assemble into a stable amphiphilic layer and to functionalize a solid surface, the samples were deposited on crystalline silicon chips, dried at $60^{\circ} \mathrm{C}$, and washed by a $60 \%$ ethanol solution or hot SDS at $2 \%$. The change of the wettability was evaluated by the contact angle of a sessile water drop before and after the functionalization and upon the washing steps (Fig. 3). The 4 putative Class I HFBs formed a stable layer, resistant to $60 \%$ ethanol and hot SDS, confirming that they belong to that class. On the other hand the layers of the other two putative HFBs were removed after mild washing in $60 \%$ ethanol, confirming that they belong to the Class II HFBs. A list of the selected strains with the corresponding HFB class and production yield is shown in Table 2. 


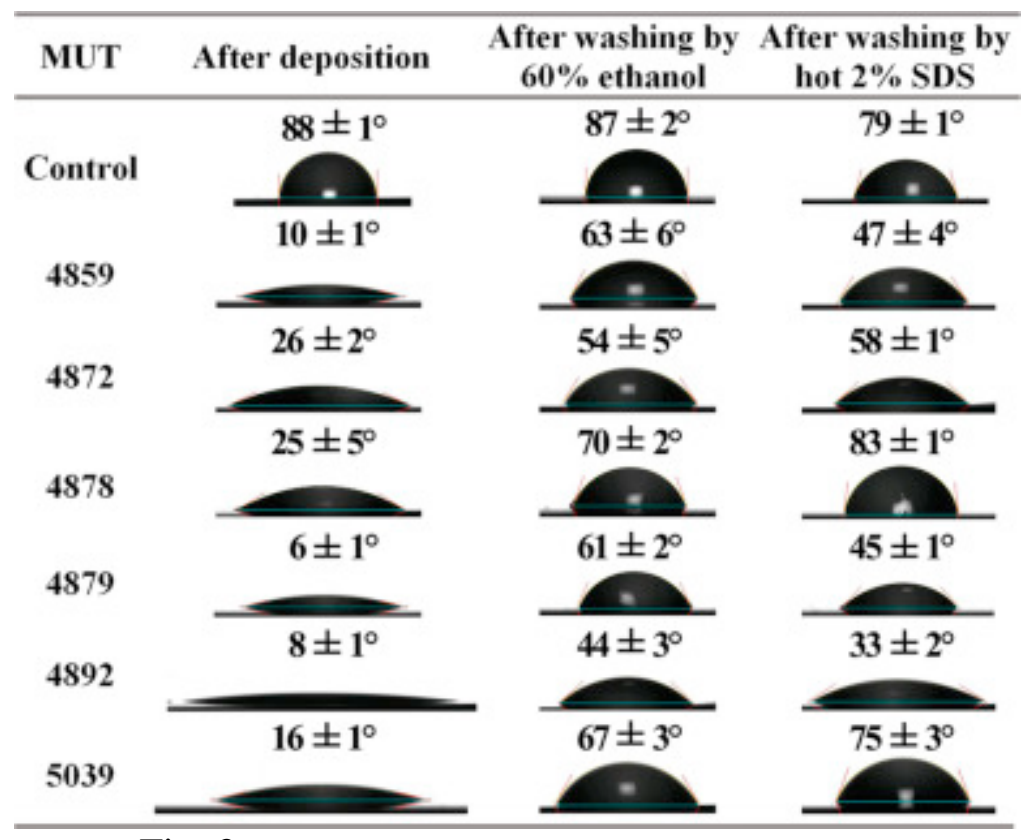

Fig. 3.

WCA analysis of crystalline silicon surface upon functionalization using the extracted HFBs and washings using different solutions.

Figure options

Table 2.

Strains selected as producers of new HFBs, classification and yield of the purified proteins.

\begin{tabular}{|c|c|c|c|}
\hline $\begin{array}{c}\text { MUT accession number and } \\
\text { strain }\end{array}$ & Source & $\begin{array}{l}\text { HFB } \\
\text { class }\end{array}$ & $\begin{array}{l}\text { Production yield, } \\
\text { mg L L }^{-1}\end{array}$ \\
\hline 4859 Roussoellaceae sp. 2 & Culture broth & $\mathrm{I}$ & 2 \\
\hline $\begin{array}{l}4872 \text { Acremonium } \\
\text { sclerotigenum }\end{array}$ & Culture broth & $\mathrm{I}$ & 10 \\
\hline 4878 Myceliophthora verrucosa & Culture broth & II & 5 \\
\hline 4879 Arthopyrenia salicis & Mycelium & II & 5 \\
\hline $\begin{array}{l}4892 \text { Penicillium } \\
\text { roseopurpureum }\end{array}$ & Culture broth & $\mathrm{I}$ & 3 \\
\hline 5039 Penicillium chrysogenum & $\begin{array}{l}\text { Mycelium and culture } \\
\text { broth }\end{array}$ & II & 12 \\
\hline
\end{tabular}

Furthermore, the emulsification capacity of each of the extracted protein was tested in the presence of olive oil upon agitation by vortex. All the six putative HFBs were able to produce water/oil emulsions (Fig. 4). Their stability was followed during one month at room temperature showing that the putative Class II HFB from the Penicillium chrysogenum MUT 5039 is the most surfaceactive protein identified in this study. 


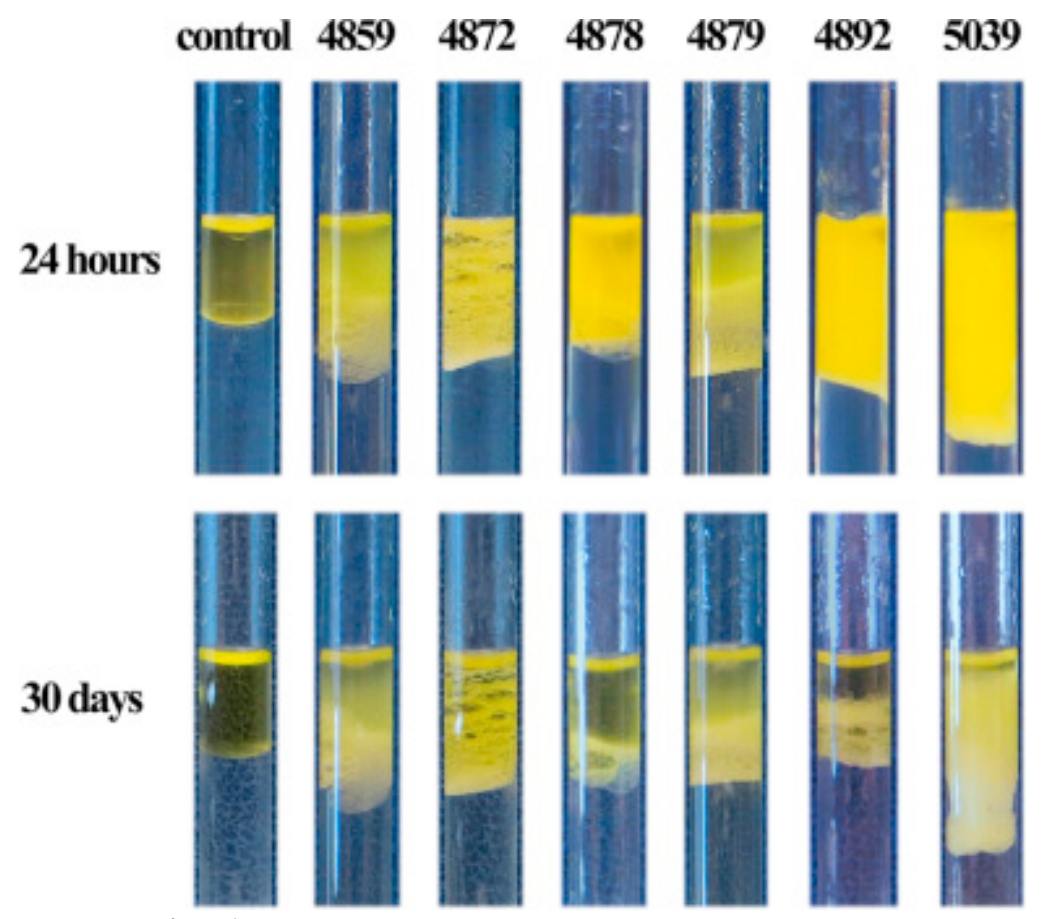

Fig. 4.

Aqueous emulsions of the extracted proteins $\left(0.05 \mathrm{mg} \mathrm{mL}^{-1}\right)$ in the presence of $25 \%$ olive oil. Each solution was vortexed for 2 min, left standing and imaged after $24 \mathrm{~h}$ and 30 days.

\section{Figure options}

\section{Conclusions}

Twenty three marine fungi, out of 100, have been selected for their ability to produce foam in shaken culture. Afterwards four extraction methods have been set up to isolate secreted or cell wall associated HFBs of Class I or II, allowing the identification of 6 new putative HFBs which show promising properties for biotechnological applications. The purity and the Mw of the proteins have been assessed by SDS-PAGE. On the basis of the stability of the amphiphilic layer that they form on a crystalline silicon chip, it has been confirmed that 4 of them belong to the Class I and 2 proteins to the Class II of the HFB family. One of them was endowed with remarkable emulsification capacity tested on a mixture of water and olive oil.

The use of marine species could enable the large scale and sustainable production of HFBs exploiting the natural resource of widely available seawater for their cultivation.

\section{Acknowledgments}

The authors would like to thank dr. Luca De Stefano and dr. Jane Politi of the Institute for Microelectronics and Microsystems, Unit of Naples, National Council of Research, for their assistance in the water contact angle measurements.

This work was supported by grant from the Ministero dell'Università e della Ricerca ScientificaIndustrial research project "Development of green technologies for production of BIOchemicals and their use in preparation and industrial application of POLImeric materials from agricultural biomasses cultivated in a sustainable way in Campania region (BioPoliS)" PON03PE_00107_1, 
funded in the frame of Operative National Programme Research and Competitiveness 2007-2013 D. D. Prot. N. 713/Ric. 29/10/2010.

\section{References}

[1] A. Cooper, M.W. Kennedy, Biofoams and natural protein surfactants Biophys. Chem., 151 (2010), pp. 96-104 http://dx.doi.org/10.1016/j.bpc.2010.06.006

[2] W. Wohlleben, T. Subkowski, C. Bollschweiler, B. von Vacano, Y. Liu, W. Schrepp, et al. Recombinantly produced hydrophobins from fungal analogues as highly surface-active performance proteins Eur. Biophys. J., 39 (2010), pp. 457-468 http://dx.doi.org/10.1007/s00249-009-0430-4

[3] J. Hakanpää, A. Paananen, S. Askolin, T. Nakari-Setälä, T. Parkkinen, M. Penttilä, et al. Atomic resolution structure of the HFBII hydrophobin, a self-assembling amphiphile, J. Biol. Chem., 279 (2004), pp. 534-539 http://dx.doi.org/10.1074/jbc.M309650200

[4] A.H. Kwan, R.D. Winefield, M. Sunde, J.M. Matthews, R.G. Haverkamp, M.D. Templeton, et al. Structural basis for rodlet assembly in fungal hydrophobins Proc. Natl. Acad. Sci. U. S. A., 103 (2006), pp. 3621-3626 http://dx.doi.org/10.1073/pnas.0505704103

[5] H. a Wösten, M.L. de Vocht, Hydrophobins, the fungal coat unravelled, Biochim. Biophys. Acta, 1469 (2000), pp. 79-86 htt://www.ncbi.nlm.nih.gov/ubmed/10998570

[6] H.A. Wösten Hydrophobins: multipurpose proteins Annu. Rev. Microbiol., 55 (2001), pp. 625646 http://dx.doi.org/10.1146/annurev.micro.55.1.625

[7] S. Zhang, Y.X. Xia, B. Kim, N.O. Keyhani, Two hydrophobins are involved in fungal spore coat rodlet layer assembly and each play distinct roles in surface interactions, development and pathogenesis in the entomopathogenic fungus, Beauveria bassiana Mol. Microbiol., 80 (2011), pp. 811-826 http://dx.doi.org/10.1111/j.1365-2958.2011.07613.x

[8] J. Bayry, V. Aimanianda, J.I. Guijarro, M. Sunde, J.-P. Latgé, Hydrophobins-unique fungal proteins PLoS Pathog., 8 (2012), p. e1002700, http://dx.doi.org/10.1371/journal.ppat.1002700

[9] M.B. Linder, G.R. Szilvay, T. Nakari-Setälä, M.E. Penttilä Hydrophobins: the proteinamphiphiles of filamentous fungi FEMS Microbiol. Rev., 29 (2005), pp. 877-896 http://dx.doi.org/10.1016/j.femsre.2005.01.004

[10] I. Macindoe, A.H. Kwan, Q. Ren, V.K. Morris, W. Yang, J.P. Mackay, et al., Self-assembly of functional, amphipathic amyloid monolayers by the fungal hydrophobin EAS Proc. Natl. Acad. Sci. U. S. A., 109 (2012), pp. E804-11 http://dx.doi.org/10.1073/pnas.1114052109

[11] V. Lo, Q. Ren, C. Pham, V. Morris, A. Kwan, M. Sunde, Fungal hydrophobin proteins produce self-assembling protein films with diverse structure and chemical stability Nanomaterials, 4 (2014), pp. 827-843 http://dx.doi.org/10.3390/nano4030827

[12] H.A.B. Wösten, K. Scholtmeijer, Applications of hydrophobins: current state and perspectives Appl. Microbiol. Biotechnol., 99 (2015), pp. 1587-1597 http://dx.doi.org/10.1007/s00253-0146319-x 
[13] M. Khalesi, K. Gebruers, G. Derdelinckx, Recent advances in fungal hydrophobin towards using in industry, Protein J., 34 (2015), pp. 243-255 http://dx.doi.org/10.1007/s10930-015-9621-2

[14] A.M. Gravagnuolo, E. Morales-Narváez, C.R.S. Matos, S. Longobardi, P. Giardina, A. Merkoçi, On-the-spot immobilization of quantum dots, graphene oxide, and proteins via hydrophobins, Adv. Funct. Mater., 25 (2015), pp. 6084-6092 http://dx.doi.org/10.1002/adfm.201502837

[15] E. Patel, P. Cicatiello, L. Deininger, M.R. Clench, G. Marino, P. Giardina, et al., A proteomic approach for the rapid, multi-informative and reliable identification of blood, Analyst, 141 (2016), pp. 191-208 http://dx.doi.org/10.1039/c5an02016f

[16] L. Panno, M. Bruno, S. Voyron, A. Anastasi, G. Gnavi, L. Miserere, et al., Diversity, ecological role and potential biotechnological applications of marine fungi associated to the seagrass Posidonia oceanica New Biotechnol., 30 (2013), pp. 685-694

http://dx.doi.org/10.1016/j.nbt.2013.01.010

[17] S.K. Satpute, A.G. Banpurkar, P.K. Dhakephalkar, I.M. Banat, B.A. Chopade, Methods for investigating biosurfactants and bioemulsifiers: a review, Crit. Rev. Biotechnol., 30 (2010), pp. 127-144 http://dx.doi.org/10.3109/07388550903427280

[18] G.M. König, S. Kehraus, S.F. Seibert, A. Abdel-Lateff, D. Müller Natural products from marine organisms and their associated microbes, ChemBioChem, 7 (2006), pp. 229-238 http://dx.doi.org/10.1002/cbic.200500087

[19] R. Nicoletti, A. Trincone, Bioactive compounds produced by strains of penicillium and talaromyces of marine origin, Mar. Drugs, 14 (2016) http://dx.doi.org/10.3390/md14020037

[20] G. Gnavi, E. Ercole, L. Panno, A. Vizzini, G.C. Varese, Dothideomycetes and Leotiomycetes sterile mycelia isolated from the Italian seagrass Posidonia oceanica based on rDNA data, Springerplus, 3 (2014), p. 508 http://dx.doi.org/10.1186/2193-1801-3-508

[21] L. Garzoli, G. Gnavi, F. Tamma, S. Tosi, G.C. Varese, A.M. Picco, Sink or swim: updated knowledge on marine fungi associated with wood substrates in the Mediterranean Sea and hints about their potential to remediate hydrocarbons, Prog. Oceanogr., 137 (2015), pp. 140-148 http://dx.doi.org/10.1016/j.pocean.2015.05.028

[22] A. Micheluz, S. Manente, V. Tigini, V. Prigione, F. Pinzari, G. Ravagnan, et al., The extreme environment of a library: xerophilic fungi inhabiting indoor niches, Int. Biodeterior. Biodegrad., 99 (2015), pp. 1-7 http://dx.doi.org/10.1016/j.ibiod.2014.12.012

Corresponding author at: Department of Chemical Sciences, Complesso Universitario Monte S. Angelo, Via Cintia 4, 80126 Naples, Italy. 